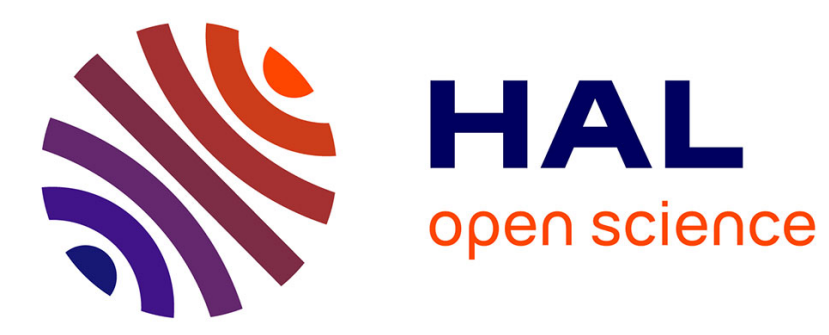

\title{
Reliability-based analysis and design of obliquely loaded footings
}

\author{
Abdul-Hamid Soubra, Dalia S Youssef Abdel Massih
}

\section{To cite this version:}

Abdul-Hamid Soubra, Dalia S Youssef Abdel Massih. Reliability-based analysis and design of obliquely loaded footings. ASCE Geo-Denver 2007, 2007, Denver, United States. hal-01008821

\section{HAL Id: hal-01008821 \\ https://hal.science/hal-01008821}

Submitted on 22 Sep 2018

HAL is a multi-disciplinary open access archive for the deposit and dissemination of scientific research documents, whether they are published or not. The documents may come from teaching and research institutions in France or abroad, or from public or private research centers.
L'archive ouverte pluridisciplinaire HAL, est destinée au dépôt et à la diffusion de documents scientifiques de niveau recherche, publiés ou non, émanant des établissements d'enseignement et de recherche français ou étrangers, des laboratoires publics ou privés. 


\title{
Reliability-based analysis and design of obliquely loaded footings
}

\author{
Abdul-Hamid Soubra ${ }^{1}$, M. ASCE and Dalia S. Youssef Abdel Massih ${ }^{2}$ \\ 1 Professor, University of Nantes, GeM, UMR CNRS 6183, Bd. de l'université, BP \\ 152, 44603 Saint-Nazaire cedex, France. E-mail: Abed.Soubra@univ-nantes.fr \\ 2 PhD Student, University of Nantes \& Lebanese University, BP 11-5147, Beirut, \\ Lebanon. E-mail: Dalia.Youssef@univ-nantes.fr
}

\begin{abstract}
This paper presents a reliability-based approach for the analysis and design of a shallow strip footing subjected to an inclined load. The deterministic model used is based on the upper-bound method of limit analysis. Both the punching and sliding modes of failure are considered. The random variables used in the analysis are the soil shear strength parameters and the vertical and horizontal components of the footing load. The reliability index of each mode and the system failure probability were calculated. It was shown that for small values of the vertical component of the footing load, the sliding mode is dominant. When this vertical component increases, the punching mode becomes more critical. The hypothesis of uncorrelated shear strength parameters was found to be conservative in comparison to the one of negatively correlated variables. The coefficients of variation of only the angle of internal friction and the horizontal footing load have a significant effect on the system failure probability. For design, an iterative procedure is performed to determine the breadth of the footing for a target failure probability.
\end{abstract}

\section{Introduction}

Geotechnical engineers have always recognized the presence of uncertainty in the analysis and design. Traditional deterministic models are based on simplified approaches. The uncertainties are taken into account through the use of a global safety factor which is essentially a 'factor of ignorance'. This factor does not reflect the effect of the inherent uncertainty of each parameter. A reliability-based analysis or design is more rational since it accounts for the inherent uncertainty of each input variable. Nowadays, this is possible because of the improvement of our knowledge on the statistical properties of the soil (e.g. Phoon and Kulhawy, 1999). 
Several authors have investigated the reliability-based analysis of foundations. Some of them (e.g. Fenton and Griffiths 2005; Przewlocki 2005 and Popescu et al. 2005 among others) have modelled the uncertain parameters as random processes and have examined the effect of the spatial variability of these parameters on the settlement or on the bearing capacity of foundations. Other authors have modelled the uncertainties of the different parameters as random variables and have conducted a reliability-based analysis by using empirical formulas for the bearing capacity factors (e.g. Cherubini 2000 and Low and Phoon 2002). These approaches have the advantage of being simple; however, they present some shortcomings because they are based on approximate formulae. Also, to the authors' knowledge, there are no extensive investigations on the reliability analysis or design of foundations subjected to an inclined load. In this paper, a reliability-based analysis and design of a strip foundation resting on a $(c-\varphi)$ soil and subjected to an inclined load is presented. Only the ultimate limit state is analysed. A rigorous deterministic limit analysis model is used. The uncertainties of the soil shear strength parameters and the vertical and horizontal components of the footing load are modelled as random variables. After a brief description of the basic concepts of the theory of reliability, the deterministic model is first presented and then, the probabilistic numerical results based on this model are presented and discussed.

\section{Basic reliability concepts}

Two different measures are commonly used in literature to describe the reliability of a structure: The reliability index and the failure probability. The reliability index of a geotechnical structure is a measure of the safety that takes into account the inherent uncertainties of the input variables. The widely used reliability index is the one defined by Hasofer and Lind (1974). Its matrix formulation is given by:

$$
\beta_{H L}=\min _{x \in F} \sqrt{(x-\mu)^{T} C^{-1}(x-\mu)}
$$

in which $x$ is the vector representing the $n$ random variables, $\mu$ is the vector of their mean values, $C$ is their covariance matrix and $F$ is the failure region. The minimisation of (1) is performed over the failure domain, $F$, corresponding to the region $G(x) \leq 0$ where the hyper-surface $G(x)=0$, referred to as the limit state surface, separates the $n$ dimensional domain of random variables in two regions: a failure region represented by $G(x) \leq 0$ and a safe region given by $G(x)>0$. The classical approach for computing the $\beta_{H L}$ reliability index by using (1) is based on the transformation of the limit state surface into the space of standard normal uncorrelated variates. The shortest distance from the transformed failure surface to the origin of the reduced variates is the reliability index $\beta_{H L}$. An intuitive interpretation of the reliability index was suggested in Low and Tang (1997) where the concept of an expanding ellipse led to a simple method of computing the HasoferLind reliability index in the original space of the random variables. These authors stated that the minimization of the reliability index is equivalent to find the smallest 
dispersion ellipsoid that is tangent to the limit state surface. When the random variables are non-normal and correlated, the optimisation approach uses the Rackwitz-Fiessler equivalent normal transformation without the need to diagonalize the correlation matrix as shown in Low (2005). The computations of the equivalent normal mean $\mu^{N}$ and equivalent normal standard deviation $\sigma^{N}$ for each trial design point are automatically found during the constrained optimization search. The method of computation of the reliability index using the concept of an expanding ellipse suggested by Low and Tang (1997) is used in this paper. From the Hasofer-Lind reliability index $\beta_{H L}$, one can approximate the failure probability by using the First Order Reliability Method FORM as follows: $P_{f} \approx \Phi\left(-\beta_{H L}\right)$, where $\Phi(\cdot)$ is the cumulative distribution function of a standard normal variable. In this method, the limit state function is approximated by a hyperplane tangent to the limit state surface at the design point.

\section{Reliability analysis of strip foundations}

The aim of this paper is to perform a reliability analysis of a strip footing resting on a $c-\varphi$ soil and subjected to an inclined load. The deterministic model used is based on the upper-bound method of limit analysis. A translational non-symmetrical multiblock failure mechanism presented by Soubra (1999) is used for the calculation of the ultimate bearing capacity ( $c f$. Figure 1). It should be mentioned that this nonsymmetrical mechanism is also appropriate for the computation of the bearing capacity due to a vertical load. Although the results given by this model are upperbound solutions, they are the smallest upper-bounds against the available ones. In some cases, they are the exact solutions since they are equal to the results given by the lower-bound method. Due to uncertainties in soil shear strength parameters and applied load, the cohesion $c$, the angle of internal friction $\varphi$, the vertical and horizontal components of the applied load (i.e. $V$ and $H$ ) are considered as random variables. Two modes of failure may occur. These are the punching and the sliding along the soil-footing interface. The performance function of the punching mode is defined with respect to the bearing failure of the soil. It is given by: $G_{1}=V_{u} / V-1$, where $V_{u}$ and $V$ are the vertical components of the ultimate foundation load and the service applied load respectively. One may use another performance function as $G_{1}=V_{u}-V$. However, this leads exactly to the same value of the punching reliability index since the Hasofer-Lind reliability index is not dependent of the definition of the performance function. Notice however that the first definition has an advantage over the second one since it makes it possible to introduce the concept of the safety factor as follows: $G_{1}=F_{p}-1$. Concerning the sliding mode of failure, the performance function is given by: $G_{2}=(a B+V \tan \delta) / H-1$ (which is equivalent to $\left.G_{2}=(a B+V \tan \delta)-(H)\right)$, where $\delta$ is the angle of friction at the soil-footing interface, $a$ is the adhesion stress and $H$ is the horizontal component of the service applied load. It is assumed that $a=c \tan \delta / \tan \varphi$ and $\delta$ is taken equal to $2 \varphi / 3$. Notice that the two performance functions depend on $H, V, c$ and $\varphi$. This is because 
$V_{u}$ in the punching performance function is not only function of $c$ and $\varphi$, but also depends on $\mathrm{H}$.

In this paper, one literally sets up a tilted ellipsoid in a spreadsheet and minimizes the dispersion ellipsoid subject to the constraint that it be tangent to the limit state surface. For the punching mode, the determination of the reliability index is performed by minimization of equation (1) not only with respect to the random variables $(c, \varphi, V, H)$, but also with respect to the geometrical parameters of the failure mechanism $\left(\alpha_{i}, \beta_{i}\right)$ where $(\mathrm{i}=1, \ldots, \mathrm{n}), \mathrm{n}$ being the number of rigid blocks in the failure mechanism. $n$ is taken equal to 12 . Therefore, the minimization is performed with respect to 28 parameters $\left(\alpha_{i}, \beta_{i}, c, \varphi, V, H\right)$. The obtained surface corresponding to the minimum reliability index is referred to here as the critical probabilistic surface. The reliability index obtained using this surface is smaller (i.e. more critical) than the one calculated by using the critical deterministic surface.

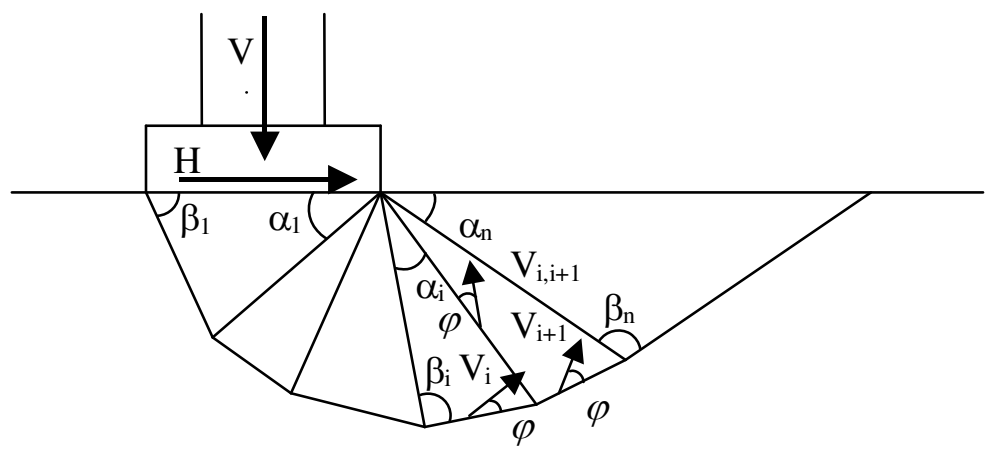

Figure 1: Non-symmetrical multiblock failure mechanism

\section{Numerical results}

The numerical results presented in this paper consider the case of a strip foundation with breadth $B=2 \mathrm{~m}$. The soil has a unit weight of $18 \mathrm{kN} / \mathrm{m}^{3}$. The illustrative values used for the statistical moments of the shear strength parameters and their coefficient of correlation $\rho_{c, \varphi}$ are given as follows: $\mu_{c}=20 \mathrm{kPa}, \mu_{\varphi}=30^{\circ}$, $\operatorname{COV}_{c}=20 \%, \operatorname{COV}_{\varphi}=10 \%$ and $\rho_{c, \varphi}=-0.5$. For the statistical moments of the vertical and horizontal applied loads, the mean values were chosen smaller than the ones corresponding to the deterministic failure load. For the vertical load, a small coefficient of variation of $10 \%$ is considered. In contrast, the horizontal load exhibits high uncertainties due to highly uncertain loads (wind, earthquake, etc.). Consequently, a relatively large coefficient of variation of $40 \%$ was taken. No correlation is considered between the horizontal and vertical applied loads. For the probability distribution of the random variables, two cases are studied. In the first case referred to as normal variables, $c, \varphi, V$ and $H$ are considered as normal variables. In the second case referred to as non-normal variables, $c, V$ and $H$ are assumed to be log-normally distributed while $\varphi$ is assumed to be bounded and a beta distribution is used (e.g. Fenton and Griffiths, 2003). The parameters of the beta 
distribution are determined from the mean value and standard deviation of $\varphi$. For both cases, either correlated or uncorrelated shear strength parameters are considered.

Reliability indexes, design points and system failure probability. As mentioned before, two modes of failure may occur. Consequently, two values of the reliability index corresponding to each mode are calculated. Table (1) presents the reliability results [i.e. Hasofer-Lind reliability index of the two failure modes, the corresponding design points $\left(c^{*}, \varphi^{*}, V^{*}, H^{*}\right)$ and the system failure probability $\left.P_{f_{s s}}\right]$ for different values of the mean vertical applied load $\mu_{V}$ and for a given prescribed value of the horizontal applied load $\mu_{H}=50 \mathrm{kN} / \mathrm{m}$. The system failure probability under the two failure modes involving the sliding and the punching of the footing is given by : $P_{f_{s s s}}=P_{f}(P \cup S)=P_{f}(P)+P_{f}(S)-P_{f}(P \cap S)$, where $P_{f}(P \cap S)$ is the failure probability under the Punching and the Sliding failure modes and, $P_{f}(P)$ and $P_{f}(S)$ are the failure probabilities under the Punching and Sliding failure modes respectively.

Table 1: Reliability results for different values of the mean vertical applied load

\begin{tabular}{|c|c|c|c|c|c|c|c|c|c|c|c|c|}
\hline \multirow{2}{*}{$\begin{array}{c}\mu_{V} \\
\mathbf{k N} / \mathbf{m}\end{array}$} & \multicolumn{4}{|c|}{$\begin{array}{c}\text { Punching mode } \\
\text { Reliability }\end{array}$} & \multicolumn{4}{|c|}{$\begin{array}{c}\text { Sliding mode } \\
\text { reliability }\end{array}$} & \multicolumn{3}{|c|}{$\begin{array}{c}\text { System } \\
\text { Reliability }\end{array}$} \\
\cline { 2 - 15 } & $\begin{array}{c}c^{*} \\
\mathbf{k P a}\end{array}$ & $\begin{array}{c}\varphi^{*} \\
(\circ)\end{array}$ & $\begin{array}{c}H^{*} \\
\mathbf{k N} / \mathbf{m}\end{array}$ & $\begin{array}{c}V^{*} \\
\mathbf{k N} / \mathbf{m}\end{array}$ & $\beta_{H L}$ & $\begin{array}{c}c^{*} \\
\mathbf{k P a}\end{array}$ & $\begin{array}{c}\varphi^{*} \\
(\circ)\end{array}$ & $\begin{array}{c}H^{*} \\
\mathbf{k N} / \mathbf{m}\end{array}$ & $\begin{array}{c}V^{*} \\
\mathbf{k N} / \mathbf{m}\end{array}$ & $\beta_{H L}$ & $\begin{array}{c}P_{f_{s y s}} \\
\%\end{array}$ & $\beta_{s y s}$ \\
\hline 200 & 17.6 & 27.9 & 131.2 & 191.2 & 2.87 & 18.7 & 28.9 & 91.0 & 192.5 & 1.83 & 3.36 & 1.83 \\
\hline 300 & 16.8 & 26.7 & 151.6 & 288.4 & 3.37 & 18.7 & 28.2 & 120.4 & 283.6 & 2.61 & 0.46 & 2.61 \\
\hline 400 & 15.9 & 25.1 & 148.4 & 393.0 & 3.58 & 18.7 & 27.7 & 148.3 & 372.8 & 3.19 & 0.08 & 3.17 \\
\hline 500 & 14.7 & 22.5 & 98.2 & 522.2 & 3.51 & 18.7 & 27.3 & 175.1 & 460.7 & 3.65 & 0.03 & 3.39 \\
\hline 600 & 14.9 & 22.4 & 67.7 & 641.9 & 3.15 & 18.7 & 26.9 & 201.0 & 547.5 & 4.04 & 0.09 & 3.14 \\
\hline 700 & 15.5 & 23.0 & 59.2 & 746.8 & 2.77 & 18.8 & 26.5 & 226.1 & 633.5 & 4.38 & 0.28 & 2.77 \\
\hline 1300 & 18.0 & 27.0 & 48.5 & 1333.1 & 1.14 & 18.9 & 25.1 & 365.8 & 1136.7 & 5.75 & 12.75 & 1.14 \\
\hline 1700 & 19.0 & 28.8 & 47.0 & 1710.6 & 0.43 & 19.0 & 24.4 & 451.8 & 1464.2 & 6.36 & 33.26 & 0.43 \\
\hline 2100 & 19.6 & 30.0 & 46.4 & 2089.6 & 0.00 & 19.0 & 23.8 & 533.7 & 1787.4 & 6.84 & 50.00 & 0.00 \\
\hline
\end{tabular}

For small values of the vertical footing load, the sliding mode is most likely to occur and no punching mode is expected. Thus, the punching reliability index increases with the increase of $\mu_{V}$. In contrast, for high values of the vertical footing load, the punching mode becomes the most critical mode of failure. An increase in $\mu_{V}$ decreases the punching reliability index. This observation explains why the punching reliability index first increases and then decreases with the vertical footing load $\mu_{V}$ for a prescribed value of the horizontal load. Concerning the sliding reliability index, it continuously increases with $\mu_{V}$ since the resisting force in the sliding performance function continuously increases with $\mu_{V}$.

The value of the system reliability index is very close to the minimum value of the two modes (cf. last column in Table 1). Hence, only a single mode of failure is 
predominant in the computation of the failure probability of the system. For small values of the vertical footing load, the sliding mode is dominant. When this vertical component increases, the punching mode becomes more critical. The value of $H^{*}$ increases in the sliding mode with the increase of $\mu_{V}$. This is because when the vertical applied load increases a higher $\mathrm{H}$ is needed to reach sliding failure. For the punching mode, when the sliding mode is predominant (i.e. for small values of $\mu_{V}$ ), $H^{*}$ behaves in the same way as for the sliding mode (i.e. increases). However, it decreases when the punching mode dominates. The values of the design points can give information about the resistance and load factors of the different random variables as follows: $F_{c}=\mu_{c} / c^{*}, \quad F_{\varphi}=\tan \left(\mu_{\varphi}\right) / \tan \varphi^{*}, \quad \gamma_{H}=H^{*} / \mu_{H}$, $\gamma_{V}=V^{*} / \mu_{V}$. Table (2) presents the obtained results for different values of the mean vertical load $\mu_{V}$. For the particular $\mu_{V}$-values of $500 \mathrm{kN} / \mathrm{m}$ and $600 \mathrm{kN} / \mathrm{m}$ corresponding to punching safety factors $F_{p}\left(F_{p}=V_{u} / V\right)$ of 3.31 and 2.89 which are close to the practical value of 3 and for which the sliding safety factors $F_{s}$ $\left(F_{s}=(a B+V \tan \delta) / H\right)$ are greater than the practical value of 1.5 , the $F_{c}$ and $F_{\varphi}$ safety factors of the soil shear strength parameters vary between 1 and 1.4 for the two failure modes. These values are within the range proposed by Eurocode 7 . In the punching mode, the vertical load factor $\gamma_{V}$ was found to be very close to one which is in conformity with Eurocode 7. In contrast, in the sliding mode, this factor was found smaller than one. This means that in this case, the vertical load behaves as a resistant parameter. For the horizontal load factor $\gamma_{H}$, high values were detected in both the punching and sliding modes. This may be explained by the choice of a high coefficient of variation for the horizontal load reflecting the importance of the uncertainties of this variable especially while studying the sliding failure mode.

Table 2: Resistance and load factors

\begin{tabular}{|c|c|c|c|c|c|c|c|c|}
\hline \multirow{2}{*}{$\begin{array}{c}\mu_{V} \\
\mathbf{k N} / \mathbf{m}\end{array}$} & \multicolumn{2}{|c|}{ Punching mode reliability } & \multicolumn{4}{c|}{ Sliding mode reliability } \\
\cline { 2 - 9 } & $F_{c}$ & $F_{\varphi}$ & $\gamma_{H}$ & $\gamma_{V}$ & $F_{c}$ & $F_{\varphi}$ & $\gamma_{H}$ & $\gamma_{V}$ \\
\hline 300 & 1.19 & 1.15 & 3.03 & 0.96 & 1.07 & 1.07 & 2.41 & 0.95 \\
\hline 500 & 1.36 & 1.39 & 1.96 & 1.04 & 1.07 & 1.12 & 3.50 & 0.92 \\
\hline 600 & 1.34 & 1.40 & 1.35 & 1.07 & 1.07 & 1.14 & 4.02 & 0.91 \\
\hline 700 & 1.29 & 1.36 & 1.18 & 1.07 & 1.07 & 1.16 & 4.52 & 0.90 \\
\hline 1300 & 1.11 & 1.14 & 0.97 & 1.03 & 1.06 & 1.23 & 7.32 & 0.87 \\
\hline
\end{tabular}

Figure (2) presents the variation of the system failure probability with the dimensionless vertical applied load $\mu_{V} /\left(\gamma \cdot B^{2}\right)$ when $\mu_{H}=100 \mathrm{kN} / \mathrm{m}$. It can be shown from this figure that the failure probability decreases with the increase of the mean vertical applied load when $\mu_{V}$ is small compared to $\mu_{H}$ and increases for higher values of $\mu_{V}$. As mentioned before, two regions are detected: a zone where sliding dominates and another one where punching is the most critical. 
Effect of correlation on the reliability index. Figures (3a, b) show the variation of the reliability index with the safety factor for the punching and sliding modes. For the punching failure mode ( $c f$. Figure 3a), a constant horizontal force of $50 \mathrm{kN} / \mathrm{m}$ was applied to the footing. However, for the sliding failure mode ( $c f$. Figure $3 b$ ), a constant vertical load of $500 \mathrm{kN} / \mathrm{m}$ was applied. The cases of normal and non-normal variables with or without correlation between the shear strength parameters are considered. The reliability index corresponding to uncorrelated shear strength parameters is smaller than the one of negatively correlated variables for both normal and non-normal probability distributions (see Mostyn and $\mathrm{Li}$, 1993). The difference is most significant for the punching mode. From Figure (3a), it can be seen that for large $\beta_{P}$-values $\left(\beta_{P}>3\right)$ for which sliding is excluded; each $\beta_{P}$ corresponds to two different values of the punching safety factor $F_{p}$. This may be explained with the aid of the interaction diagram (corresponding to $F=1$ ) and the similar in shape curves corresponding to different other values of $F$ since all these curves give two values of the vertical load for a prescribed value of the horizontal load.

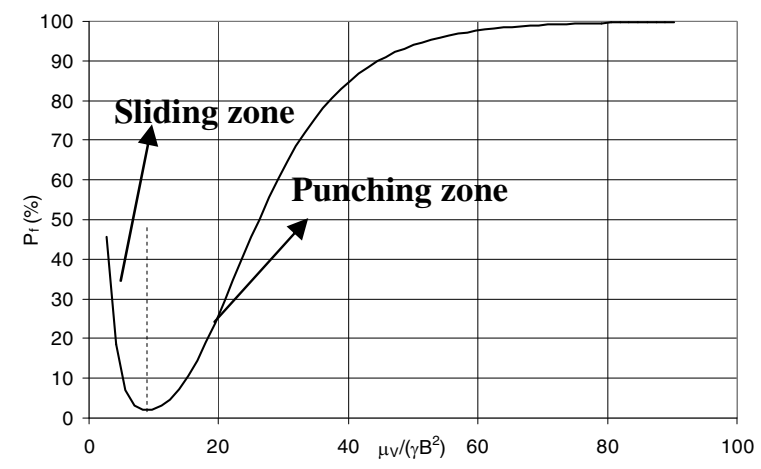

Figure 2: Failure probability versus $\mu_{V} /\left(\gamma \cdot B^{2}\right)$

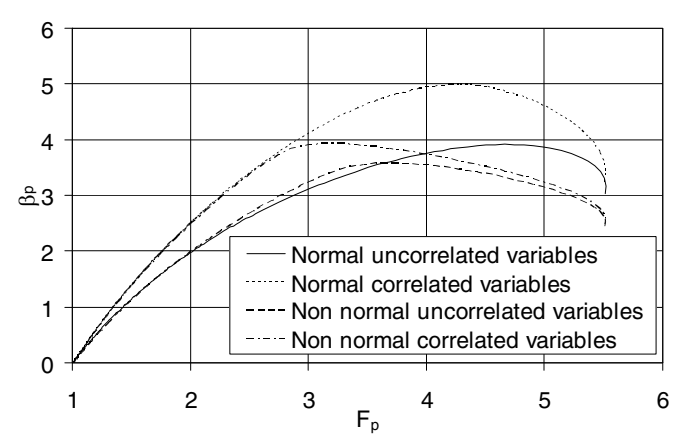

a) Punching mode

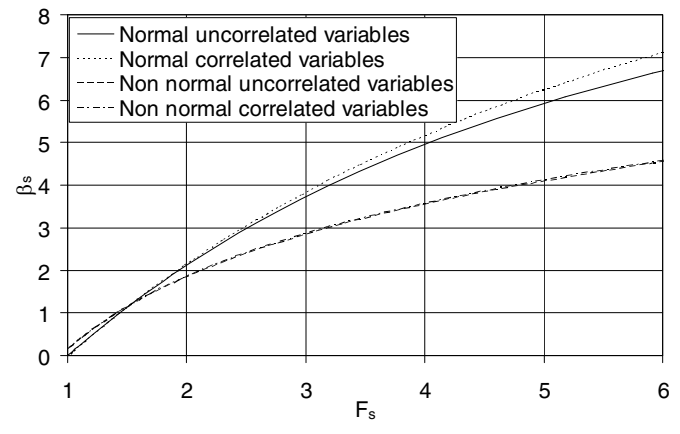

b) Sliding mode

Figure 3: Reliability index versus safety factor for the two failure modes

Effect of the variability of each random variable on the CDF of the punching and sliding safety factors. Figures $(4 a, b)$ show the effect of the coefficient of variation of each random variable on the $C D F \mathrm{~s}$ of the punching and sliding safety factors. Five cases are considered. The first case, referred to as "reference case", 
considers the values of the coefficients of variation as given in the introduction of the section named "numerical results". The other cases correspond to an increase by 10 $\%$ of the coefficient of variation of each variable. It can be seen that a small variation of the coefficient of variation of $\varphi$ highly affects the $C D F$ curve of the punching safety factor. One can also notice that the $C D F$ curve is slightly sensitive to a variation of the other variables uncertainty. This may be explained as follows: For $\mu_{\varphi}=30^{\circ}$, a variation by $10 \%$ in $\operatorname{COV}_{\varphi}$ will result in a variation of $\varphi$ between $27^{\circ}$ and $33^{\circ}$ which will highly affect the value of the ultimate load and consequently results in a high variation in the failure probability. An increase by $10 \%$ in the coefficient of variation of the vertical load has also a high effect on the failure probability compared to $c$ and $H$, but its effect continues to be negligible compared to $\varphi$. Concerning the $C D F$ curve of the sliding safety factor, it is significantly affected by a small variation of $C O V_{H}$ since a small variation in $H$ greatly affects the footing sliding stability.

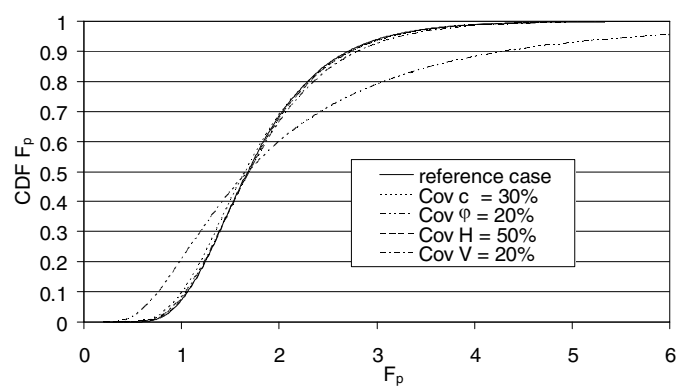

a) Punching mode

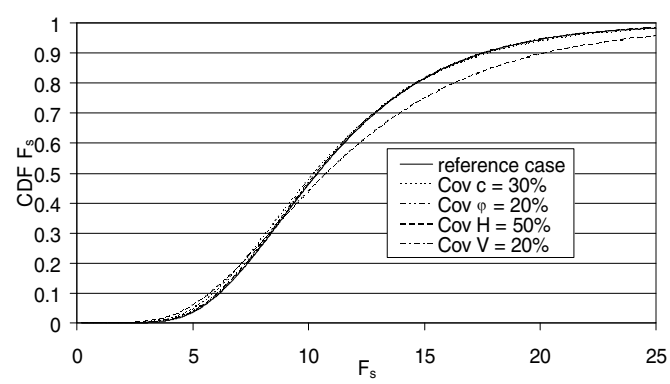

b) Sliding mode

Figure 4: CDFs of the safety factors

As a conclusion, the system failure probability is highly influenced by the coefficients of variation of $\varphi$ and $H$. Thus, the accurate determination of the uncertainties of the angle of internal friction $\varphi$ and the horizontal footing load is very important in obtaining reliable probabilistic results. In contrast the coefficients of variation of $c$ and $V$ do not significantly affect the failure probability.

Probabilistic design. The conventional deterministic approach used in the design of a shallow foundation consists in prescribing a target safety factor (generally $F_{p}=3$ for the punching mode and $F_{s}=1.5$ for the sliding mode) and determining the corresponding breadth of the footing $B$. In this section, a probabilistic design is presented. It consists in the calculation of $B$ for a system target reliability index of 3.8 as suggested by Eurocode 7 for the ultimate limit states. The mean values of the applied loads were taken equal to $\mu_{V}=500 \mathrm{kN} / \mathrm{m}$ and $\mu_{H}=50 \mathrm{kN} / \mathrm{m}$. Figure (5) presents the probabilistic foundation breadth for different values of the coefficients of variation of the random variables and for different coefficients of correlation of the shear strength parameters. The case of non-normal variables is considered. This figure also presents the deterministic breadth corresponding to a punching safety factor of 3 for which the sliding safety factor was checked to be higher than 1.5. 
Since it was shown in the previous section that the accurate determination of the uncertainties of the angle of internal friction $\varphi$ and the horizontal footing load is very important in obtaining reliable probabilistic results, only the effect of the coefficients of variation of these variables on the probabilistic breadth is presented. From figure (5), one can notice that the probabilistic foundation breadth decreases with the increase of the negative correlation between the shear strength parameters and the decrease of the coefficients of variation of the random variables. It can become smaller than the deterministic breadth for small values of the coefficient of variation of the horizontal load and for the common values of the soil variability (i.e. $C O V_{\varphi}=5-10 \%, C O V_{c}=20 \%,-0.7 \leq \rho_{c, \varphi} \leq-0.3$ ). For large values of the coefficients of variation and small correlation coefficient, the probabilistic breadth is higher than the deterministic one. As a conclusion, the deterministic footing breadth may overestimate or underestimate the probabilistic one according to the values of the uncertainties. Contrary to Eurocode 7 which prescribes constant values of the resistance and load factors $\left(F_{c}, F_{\varphi}, \gamma_{V}\right.$ and $\left.\gamma_{H}\right)$, the present Reliability Based Design $R B D$ has the advantage of providing different values of these factors depending on the soil variability. These factors are the optimal ones and are determined rigorously by a maximization of the failure probability for a given soil variability.

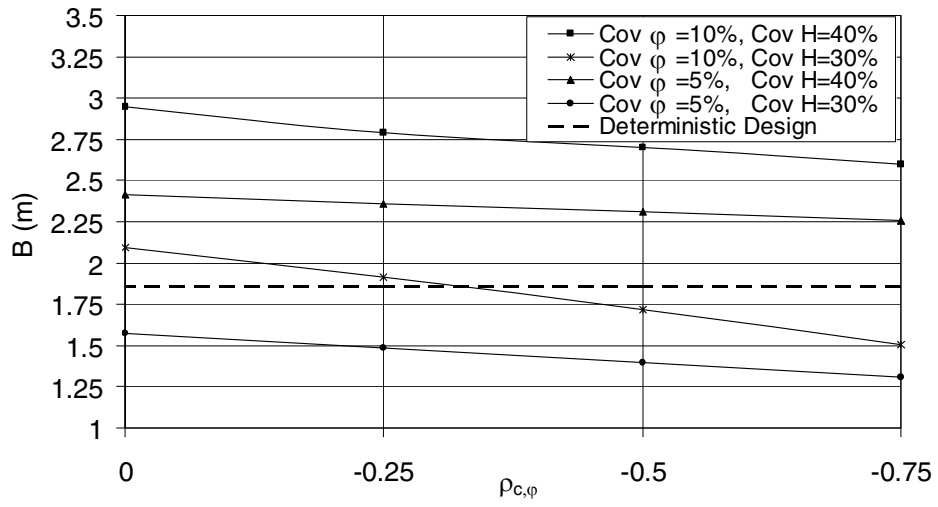

Figure 5: Comparison between deterministic and probabilistic design

\section{Conclusion}

This paper presents a reliability-based approach for the analysis and design of a shallow strip footing subjected to an inclined load. The deterministic model used is based on the upper-bound method of limit analysis. Both the punching and sliding modes of failure are considered. The random variables used in the analysis are the soil shear strength parameters and the footing applied loads. The reliability index of each mode and the system failure probability were calculated. A Reliability Based Design of the footing has been presented. The main conclusions of this paper may be summarized as follows:

It was found that only a single mode of failure (either sliding or punching) was predominant in the computation of the failure probability of the system. The negative correlation between the shear strength parameters highly increases the reliability of 
the foundation. The system failure probability was found to be significantly influenced by the coefficients of variation of $\varphi$ and $H$. The values of the design points have given information about the resistance and load factors of the random variables. It was shown that for the vertical load factor $\gamma_{V}$, its value is smaller than one in the sliding mode. This means that the vertical load behaves in this case as a resistant parameter. For the horizontal load factor $\gamma_{H}$, high values were detected in both punching and sliding modes. This can be explained by the choice of a high coefficient of variation for the horizontal load reflecting the importance of the uncertainty of this variable especially while studying the sliding failure mode. The Reliability Based Design has shown that the probabilistic foundation breadth decreases with the increase of the negative correlation between the shear strength parameters and the decrease of the coefficients of variation of the random variables. Hence, the deterministic footing breadth may overestimate or underestimate the probabilistic one according to the values of the uncertainties.

\section{References}

Cherubini, C. (2000). "Reliability evaluation of shallow foundation bearing capacity on C', $\varphi^{\prime}$ soils." Can. Geotech. J., 37, 264-269.

Fenton, G. A., and Griffiths D. V. (2003). "Bearing capacity prediction of spatially random C- $\varphi$ soils." Can. Geotech. J., 40, 54-65.

Fenton, G. A., and Griffiths, D. V. (2005). "Three-Dimensional probabilistic foundation settlement." J. of Geotech. \& Geoenv. Engrg., ASCE, 131(2), 232239.

Hasofer, A. M., and Lind, N. C. (1974). "Exact and invariant second-moment code format." J. of Engrg. Mech., ASCE, 100(1), 11-121.

Low, B. K. (2005). "Reliability-based design applied to retaining walls." Géotechnique, 55(1), 63-75.

Low, B. K., and Tang, W. H. (1997). "Efficient reliability evaluation using spreadsheet." J. of Engrg. Mech., ASCE, 123, 749-752.

Low, B. K., and Phoon, K. K. (2002). "Practical first-order reliability computations using spreadsheet." Probabilistics in Geotechnics: Technical and Economic Risk Estimation, Austria, 39-46.

Mostyn, G.R. and Li, K.S. (1993). "Probabilistic slope analysis - State-of-play." Probabilistic Methods in Geotechnical Engineering, Rotterdam, 89-109

Phoon, K.-K., and Kulhawy, F. H. (1999). "Evaluation of geotechnical property variability." Can. Geotech. J., 36, 625-639.

Popescu, R., Deodatis, G., and Nobahar, A. (2005). "Effect of random heterogeneity of soil properties on bearing capacity." Probabilistic Engrg. Mech., 20, 324341.

Przewlocki, J. (2005). "A stochastic approach to the problem of bearing capacity by the method of characteristics." Computers \& Geotechnics, 32, 370-376.

Rackwitz, R., and Fiessler, B. (1978). "Structural reliability under combined random load sequences." Computers \& Structures, 9(5), 484-494.

Soubra, A.-H. (1999). "Upper-bound solutions for bearing capacity of foundations." J. of Geotech. \& Geoenv. Engrg., ASCE, 125(1), 59-68. 